\title{
Vitamin D Supplementation during Pregnancy- A Double Blinded Randomized, Controlled, Dose- Comparison, Trial in Pakistan
}

\section{Sidrah Nausheen ( $\nabla$ sidrah.nausheen@aku.edu )}

Aga Khan University

Lumaan Shaikh

Aga Khan University

Atif Habib

Aga Khan University

Farhana Tabassum

Aga Khan University

Arjumand Rizvi

Aga Khan University

Maria Bhura

Aga Khan University

Sumra Kureishy

Aga Khan University

Fariha Shaheen

Aga Khan University

Shahmim Raza

Aga Khan University

Sajid Bashir Soofi ( $\square$ sajid.soofi@aku.edu )

Aga Khan University

\section{Research Article}

Keywords: Vitamin D, cholecalciferol, nutrients, micronutrients, deficiency, pregnancy, supplement

Posted Date: July 15th, 2020

DOI: https://doi.org/10.21203/rs.3.rs-41122/v1

License: (1) (1) This work is licensed under a Creative Commons Attribution 4.0 International License.

Read Full License 


\section{Abstract}

Vitamin D deficiency during pregnancy is a public health problem in Pakistan, and prevalent among most women of reproductive age in the country. Vitamin D supplementation during pregnancy is suggested to prevent adverse pregnancy outcomes and prevent vitamin $D$ deficiency in both the mother and her newborn. However, there remains uncertainty surrounding the appropriate and safe dose for vitamin $D$ supplementation in pregnant women who experience deficiency. We conducted a double-blinded, randomized, controlled, dose-comparison trial aimed to evaluate the relationship between different doses of vitamin D supplementation during pregnancy and pregnancy outcomes among women in a maternity hospital of the Aga Khan University (AKU) in Karachi, Pakistan. Pregnant women ( $n=350)$ in their first trimester were recruited and randomized to three treatment groups of vitamin $D$ supplementation: 4,000 IU/day (Group A; n=120), 2,000 IU/day (Group B; n=115), or 400 IU/day (Group C - control; $n=115$ ). Deficiency in serum vitamin D (serum $250 \mathrm{HD}<20 \mathrm{ng} / \mathrm{mL}$ ) at baseline was prevalent in more than $95 \%$ of women in each group. Participants in group A had the lowest vitamin D deficiency at endline and in newborns (endline: $75.9 \%$; neonatal: $64.9 \%$ ), followed by group B (endline: $84.9 \%$; neonatal: $73.7 \%$ ) and then the control group (endline: $90.2 \%$; neonatal: $91.8 \%$ ). Vitamin D deficiency was significantly lower in group $A$ than group $C(p=0.006)$ for women at endline, and lower in both group $A$ and group $B$ than the control group $(p=0.001)$ in neonates. There were no adverse events attributable to vitamin $D$ supplementation in all groups. Our study concluded that vitamin D supplementation with $4000 \mathrm{lU} /$ day is safe and effective in reducing the risk of maternal and neonatal vitamin $D$ deficiency.

\section{Key Messages}

- Vitamin D deficiency is a significant public health issue and is prevalent in nearly all pregnant women in Pakistan.

- Due to long term and adverse health consequences associated with vitamin D, particularly among infants, public health policy needs to be strengthened to ensure that vitamin D deficiency is minimized among pregnant women and therefore in their infants.

- Guidelines regarding vitamin D supplementation during pregnancy should be revised for deficient women in at-risk populations

- More robust cohort trials need to be conducted to evaluate the effectiveness of higher doses of vitamin D supplementation in deficient populations.

\section{Introduction}

Vitamin $D$ has garnered a lot of attention in recent years due to a high global prevalence of vitamin $D$ deficiency, which is affecting more than a billion people of all ages and ethnicity (Holick \& Chen, 2008). Both developing and developed countries have produced several studies concentrated on Vitamin D deficiency in their respective populations in adults and children (Cristina Palacios \& Gonzalez, 2014; Prentice, 2008). The role of Vitamin D as a regulator of bone mineral metabolism and skeletal 
development is well-established (Bikle, 2014; Olmos-Ortiz, Avila, Durand-Carbajal, \& Díaz, 2015). It not only affects musculoskeletal health, but can also result in several acute and chronic diseases (HosseinNezhad \& Holick, 2013).

Vitamin D has also been recognized through all stages of pregnancy and postnatal development of the neonate, including calcium absorption, parathyroid hormone expression and growth-plate function (Christakos, 2012; Kumar \& Thompson, 2011; Merewood, Mehta, Chen, Bauchner, \& Holick, 2009; OlmosOrtiz et al., 2015; St-Arnaud \& Naja, 2011). Furthermore, maternal vitamin D deficiency has been commonly associated with adverse maternal and birth outcomes, such as vitamin D deficiency and hypocalcaemia in neonates, preterm birth, small for gestational age (SGA) and pre-eclampsia in metaanalyses and clinical trials (Aghajafari et al., 2013; Panda, McIntosh, Chaudhari, \& Kent, 2019; Tibbott, Camadoo, \& Isaza, 2007; C. L. Wagner et al., 2015; Wei, Qi, Luo, \& Fraser, 2013). Vitamin D deficiency and insufficiency is highly prevalent among pregnant women (Cristina Palacios \& Gonzalez, 2014). The prevalence of low vitamin $D$ status ( $<50-75 \mathrm{nmol} / \mathrm{l})$ in pregnant women is immense in South Asian and Middle Eastern countries, particularly in India (96\%), Bangladesh (64\%), Turkey (90\%), Kuwait (70-83\%), and Iran (60-80\%), where sociocultural and religious dressing trends prevent direct exposure of skin to sunlight, despite the abundance of sunshine throughout the year (De-Regil, Palacios, Lombardo, \& PenaRosas, 2016; Kazemi, Sharifi, Jafari, \& Mousavinasab, 2009; Maghbooli et al., 2007; Roth et al., 2013; Vatandost et al., 2018). Similarly, a trial from Pakistan reported vitamin D deficiency in $90.5 \%$ women (A. Khan, Naureen, Iqbal, \& Dar, 2013). The most recent National Nutrition Survey (NNS) 2018 reported a prevalence of vitamin D deficiency in 79.7\% Women of Reproductive Age (WRA), which has increased by $11-13 \%$ since the previous NNS (2011) (Government of Pakistan, 2013; Government of Pakistan \& UNICEF, 2019). Another cross-sectional study in our department found that $99.5 \%$ of women and $97.3 \%$ of their neonates were vitamin D deficient in Karachi (Anwar et al., 2016).

In order to counter the adverse effects of vitamin D deficiency, several trials have been conducted across the globe to evaluate the impact of vitamin $D$ supplementation during pregnancy on maternal and birth outcomes (Agarwal, Kovilam, \& Agrawal, 2018; De-Regil et al., 2016; Gallo et al., 2019; C. Palacios, Kostiuk, \& Pena-Rosas, 2019). However, very limited trials have been conducted in Pakistan to evaluate the preventive impact of vitamin D supplementation on adverse maternal and neonatal health outcomes. Studies conducted earlier were either unblended, did not compare different doses of vitamin D or did not present outcomes of interest (Hossain et al., 2014; A. Khan et al., 2013; F. R. Khan, Ahmad, Hussain, \& Bhutta, 2016). Moreover, the ideal dose for vitamin D supplementation has not been evaluated in order to ensure that those who are deficient can achieve sufficient levels of serum 25-hydroxyvitamin D concentrations in a country with such a high deficiency.

The need, safety and effectiveness of vitamin D during pregnancy remains controversial. There is a dearth of data and no universal agreement regarding appropriate dose of vitamin D during pregnancy, although it appears to be greater than the current dietary reference intake of $200-400 \mathrm{lU} / \mathrm{d}(5-10 \mu \mathrm{g} / \mathrm{d})$. This reassessment is critical because the current recommendations result in a high degree of vitamin $D$ deficiency. The Institute of Medicine recommends a dietary allowance of $600 \mathrm{IU} /$ day of vitamin D to 
optimize maternal bone health and ensure fetal bone growth (Institute of Medicine, 2011). Moreover, the World Health Organization only recommends pregnant women with vitamin $D$ deficiency a recommended intake of $200 \mathrm{IU}(5 \mathrm{mcg})$ a day (World Health Organization, 2016). Hollis et al reported 50\% of mothers and $65 \%$ of newborn, severely vitamin $D$ deficient at the time of birth although these mothers were taking prenatal vitamin containing $400 \mathrm{IU}$ of vitamin D and drank 2 glasses of vitamin D fortified milk (B. Hollis \& Wagner, 2004). Various studies have showed that vitamin D supplementation of $4000 \mathrm{IU} /$ day is more effective in obtaining normal serum levels of vitamin $D(32 \mathrm{ng} / \mathrm{mL})$ as compared to $400 \mathrm{IU} /$ day and 2000 IU/day in all pregnant women and newborns irrespective of race (Dawodu et al., 2013; B. W. Hollis, Johnson, Hulsey, Ebeling, \& Wagner, 2011; Mithal \& Kalra, 2014). Furthermore, pregnant women receiving $4000 \mathrm{IU} /$ day were reported to have a reduced risk of complications, preterm births, gestational diabetes, pregnancy-induced hypertension, preeclampsia and infections (Dawodu et al., 2013; B. W. Hollis et al., 2011; Mithal \& Kalra, 2014). These studies suggest pregnant women may be unable to obtain adequate serum levels of vitamin D solely through dietary sources, therefore, supplementation is essential.

We therefore initiated a randomized controlled trial among pregnant women to assess the efficacy, safety and pregnancy outcomes of vitamin D supplementation. The objectives of the study were to estimate the effective dose of vitamin D supplementation during pregnancy required to prevent vitamin D deficiency, pre-eclampsia, preterm birth, low birth weight and stillbirth rates. We also aimed to evaluate risk factors associated with vitamin $\mathrm{D}$ deficiency.

\section{Methods}

\section{Study Design, Setting \& Participants}

We conducted a double-blinded, randomized, controlled trial to assess the efficacy, safety and pregnancy outcomes of different doses of vitamin D supplementation during pregnancy in Karachi, Pakistan. The trial was carried out at Aga Khan University Hospital affiliated Hospital for Women and Children, Kharadar in Karachi, Pakistan from June 2013 until December 2015. Pregnant women less than 16 weeks gestation were eligible to participate in the study (identified through their last menstruation period), had a singleton pregnancy, and agreed to deliver at Aga Khan Hospital. Women who had a history of preexisting chronic conditions (type I or type II diabetes, chronic hypertension or chronic disease), had multiple fetuses or had a fetal anomaly identified through an ultrasound scan were not eligible to participate in the study.

\section{Sample Size and Randomization}

In order to detect a $40 \%$ reduction in vitamin D deficiency between control and intervention groups, we calculated a sample size of 315 pregnant women in total (105 women in each group) at $80 \%$ power and $5 \%$ level of significance, based on a $68 \%$ prevalence of vitamin D deficiency among pregnant Pakistani women (Government of Pakistan, 2013). To account for dropouts and lost to follow-up, the total sample size was inflated to 350 women. The data management unit of AKU created a block randomization list 
with a block size of ten to balance the number of participants allocated into the study groups. All study personnel and participants were blinded to group assignment.

\section{Study Intervention and Allocation}

Study participants were allocated into three groups of Vitamin D supplementation: 4000 IU (Group A), 2000 IU (Group B) and 400 IU (Group C). The group receiving $400 \mathrm{IU}$ of Vitamin D was treated as the control group. Vitamin D supplementation was started between $12^{\text {th }}$ to $16^{\text {th }}$ week of gestation, irrespective of their gestational age at enrollment. The randomization list was provided to the pharmacy at Aga Khan University (AKU), who prepared and packaged the supplements according to allocated dosage and unique participant IDs. The Vitamin D supplements were distributed as oral syrups in bottles that were identical in shape, size, colour and tasteThe study staff (investigators, laboratory staff, study teams and data collectors) and participants were blinded to the dose of Vitamin D allocated to participants. The allocation scheme was made available to the pharmacy in cases where individual participants need to be unmasked due to suspected supplement-related adverse events (i.e., hypercalcaemia or vitamin $\mathrm{D}$ toxicity). Women were asked to continue their prenatal vitamins and iron supplements in all three groups.

\section{Outcomes}

The primary outcome measures included pregnancy and birth outcomes, i.e. hypovitaminosis, preeclampsia, gestational diabetes mellitus (GDM), preterm birth ( $<37$ weeks gestation), low birth weight $(\leq 2500 \mathrm{~g})$ and still births (no signs of life upon delivery of baby). Based on clinical classifications, the presence of vitamin D deficiency (hypovitaminosis) was defined as serum 25-hydroxyvitamin D concentration of less than $20 \mathrm{ng} / \mathrm{ml}$, insufficiency as $20-30 \mathrm{ng} / \mathrm{ml}$, and sufficient as $30 \mathrm{ng} / \mathrm{ml}$ or greater (Holick, 2007). Pre-eclampsia was suspected through blood pressure $(>140 / 90 \mathrm{~mm} / \mathrm{Hg})$ and confirmed through a urine dipstick test or urine DR test for proteinuria ( $\geq 300 \mathrm{mg})$ (L. K. Wagner, 2004). A preeclampsia profile included platelet count, serum uric acid and liver function tests. GDM was diagnosed through glucose intolerance during an oral glucose tolerance test conducted in the second trimester of pregnancy (OGTT). Glucose intolerance was defined by fasting glucose $>92 \mathrm{mg} / \mathrm{dL}$, one-hour glucose > $180 \mathrm{mg} / \mathrm{dL}$ or two-hour glucose $>153 \mathrm{mg} / \mathrm{dL}$ (American Diabetes Association, 2012). Our secondary outcomes were to evaluate the prevalence of vitamin D deficiency in pregnant women at enrolment and evaluate risk factors associated with vitamin D deficiency such as diet, exposure to sunlight and biochemical measures (blood levels of calcium, phosphorus and alkaline phosphatase).

\section{Enrolment and Data Collection}

All eligible women were invited to participate in the study. Those who provided written consent were enrolled. Baseline information collected at enrolment included socioeconomic measures, anthropometric measurements (weight, height and BMI), gestational age. We also documented women's exposure to sunlight and dietary patterns at their baseline visit. Baseline information was collected using a standardized questionnaire by trained data collectors. Gestational age was determined based on the last 
menstrual period and dating ultrasound. Diet was evaluated through the consumption of ten food groups 24-hours prior to their visit. The food groups included: 1) Grains, white roots, tubers, plantains; 2) Pulses; 3) Nuts and seeds; 4) Dairy; 5) Meat, poultry, fish; 6) Eggs; 7) Dark green leafy vegetables; 8) Vitamin A rich fruits and vegetables; 9) Other vegetables; 10) Other fruits. Blood samples were collected to identify blood biochemical concentrations. Participants were provided with a supply of Vitamin D which was replenished at their monthly/fortnightly follow-up visit. They were instructed to consume $5 \mathrm{ml}$ (1tsp) of vitamin $\mathrm{D}$ syrup a day, which was equivalent to their allocated dosage.

Follow-up visits were conducted on a monthly basis till 28 weeks of gestation, fortnightly till 36 weeks, and then weekly till the time of delivery. During visits, women were monitored for weight gain, blood pressure, pregnancy-related complications, compliance to antenatal visit, dietary intake, exposure to sunlight, and presence of adverse effects. Twenty-four-hour dietary recalls were conducted to determine general eating patterns and assess dietary calcium and vitamin $D$ intake. Compliance to vitamin $D$ supplementation was assessed through self-reporting and evaluation of syrup bottles at each follow-up visit. After delivery, the newborn was assessed for neonatal abnormalities, gestational age, and birth weight to identify preterm births and low birth weight.

\section{Blood Samples}

Maternal blood samples were collected at baseline and prior to delivery. At delivery, cord blood samples were obtained from newborns. In the absence of cord blood samples, blood samples were collected from newborns. The blood samples were used to assess serum calcium, phosphorus, alkaline phosphatase and vitamin D levels. The samples were transported to the Nutrition Research Laboratory (NRL) at AKU for analysis. Quality control of collected samples was monitored through the National Institute of Standards and Technology Standard Reference Materials. An Electrochemiluminescence Immunoassay (ECLIA) was used to measure the serum vitamin D levels.

\section{Data Management \& Statistical Analysis}

Data was entered using databases and entry screens developed on Microsoft FoxPro. All data was double entered for accuracy and quality control. Data was analyzed using SPSS version 15. Descriptive statistics were reported through means and standard deviation for continuous variables and frequency tables for categorical variables. Means between groups were compared through an Analysis of Variance (ANOVA) test for continuous variables, and a Pearson's Chi Squared Test was conducted to establish the differences between treatment groups for categorical variables. A Fisher's Exact Test was conducted for evaluating differences between with low expected frequencies (VanPool \& Leonard, 2011). An ANOVA test was also conducted to compare the differences in mean serum vitamin $D$ levels between baseline and endline between treatment groups. Significance between groups was considered with $p<0.05$.

\section{Ethical Approval}


Ethical approval for the study was obtained from the Aga Khan University Ethical Review Committee. All participants were required to give informed written consent to participate in the study. Consent form was translated into local languages for better understanding. The study was registered at NIH ClinicalTrial.gov NCT02215213.

\section{Results}

\section{Baseline characteristics}

A total of 350 women were enrolled in the study and randomly assigned to a treatment group, with 120 women in group A (4000 IU), 115 women in group B (2000 IU) and 115 women in group C (400 IU) (Figure 1). Two hundred and fifty-seven (73.4\%) women completed the study. There were 17 miscarriages, two still-births and two early neonatal deaths in our study, so 253 neonates were assessed.

Socioeconomic characteristics were similar between treatment groups for maternal age, maternal education and occupation status, husband's education and occupation status, gestational age and anthropometric measurements (Table 1 ). The mean age among participants was $26.03 \pm 4.3$ years, and nearly $47 \%$ had attained secondary schooling or above. The average monthly income of husbands was PKR 20,446 $\pm 12,353$ (USD 128 \pm 77 ) across groups. Anthropometry at baseline showed a mean BMI of $29.4 \pm 5.9$ and gestational age at enrolment was $13.3 \pm 4.4$ weeks. There were no significantly different observations across the groups at baseline.

Our data revealed that most households (93.1\%) received an adequate amount of sunlight, and a majority $(96.3 \%)$ of women wore a veil or burqa when outside their houses, likely due to religious and cultural norms (Table 1). Food groups consumed by women 24-hours prior to their visit had a mean \pm SD of $3.74 \pm 1.09$. Five or more food groups were only consumed by $75(22.3 \%)$ women.

\section{Maternal and neonatal biochemical markers}

At baseline, mean biochemical markers did not differ across groups, except for phosphorus which was higher in the control group $(p=0.014)$. Vitamin D deficiency $(<20 \mathrm{ng} / \mathrm{mL})$ was present in $336(97.4 \%)$ women at baseline (Table 2). At endline, women in group $A$ who received 4,000 IU/day had the lowest vitamin D deficiency (75.9\%) compared to those in group B (84.9\%) and the control group $(90.2 \%$, $\mathrm{p}=0.006)$. Vitamin $\mathrm{D}$ deficiency was significantly lower among newborns in Group A (64.9\%) and Group B (73.7\%) compared to the control group (91.8\%) ( $p=0.001)$ (Table 2). Moreover, maternal 250HD was higher in group A compared to group $B$ and group $C$ respectively $(14.0 \pm 9.6 \mathrm{ng} / \mathrm{dL}$ vs. $11.9 \pm 7.7 \mathrm{ng} / \mathrm{dL}$ vs. $9.8 \pm 7.2(p=.002))$ at delivery, and neonatal vitamin $D$ concentrations at birth were higher in groups $A$ and B compared to group C (group A: $17.4 \pm 13.8 \mathrm{ng} / \mathrm{dL}$ and group B: $14.5 \pm 11.5 \mathrm{ng} / \mathrm{dL}$ vs. group C: 10.2 $\pm 7.1(p=.006)$ ) (Figure 2, Table 2). Supplementation of $4000 \mathrm{IU} /$ day showed a substantial improvement on blood concentrations of vitamin D between baseline and endline, which was not seen among other groups (Figure 2). There were no significant differences reported between groups for other biochemical deficiencies. However, our study identified a marginally higher calcium deficiency among women across 
all groups right before delivery compared to baseline levels. We observed no serious adverse events among participants in our study.

\section{Pregnancy and birth outcomes}

Our study reported a total of four (1.6\%) cases of pre-eclampsia with one each in group $A$ and $B$, and two in group $\mathrm{C}$; and 11 (4.3\%) cases of gestational diabetes with three (3.3\%) in group A, six (7.0\%) in group $B$ and two (2.2\%) in group C (Table 3 ). Pregnancy outcomes did not significantly differ across groups. With regards to birth outcomes, there were a total of $74(29.2 \%)$ preterm births in our study, with $23(29.1 \%)$ in group A, 20 (23.5\%) in group B and 31 (34.8\%) in group C. There were also 48 (19\%) occurrences of low birth weight babies, with 14 (17.7\%) in group A, 19 (22.4\%) in group B and 14 (16.9\%) in group C. We also observed two $(0.7 \%)$ still births in our study, both in the control group (Table 3$)$. None of the birth outcomes were significantly different across groups.

\section{Vitamin D exposure}

We further evaluated the overall compliance to vitamin D supplements among our study participants. Overall, 309 (90\%) participants were compliant to supplementation with slight differences between groups (group A: 107 (89.2\%), group B: 98 (86\%) and group C (94.6\%)). However, differences in compliance were not significant across groups. Moreover, we saw slightly improved dietary patterns among women, with an average consumption of $3.91 \pm 1.22$ food groups, and $75(30.7 \%)$ women consuming five or more food groups within 24-hours of their visit (Table 3).

\section{Discussion}

Vitamin D deficiency has become a widespread global health issue, particularly among pregnant women in South Asian and Middle Eastern populations (Akhtar, 2016; Bassil, Rahme, Hoteit, \& Fuleihan, 2013; Lowe \& Bhojani, 2017). To the best of our knowledge, this is the first randomized, controlled, dosecomparison trial of vitamin D supplementation among pregnant women who experience hypovitaminosis, and its impact on maternal and neonatal outcomes in Pakistan.

In our study, we found a vast majority of pregnant women (96.3\%) were deficient in vitamin D at enrolment. The prevalence of vitamin D deficiency observed is alarming and the findings in our study are similar to other studies conducted in Karachi, Pakistan, which reported deficiency in over $90 \%$ females (Anwar et al., 2016; A. Khan et al., 2013). Another cross-sectional study found vitamin D deficiency among only $46 \%$ of women in labour in Karachi (Karim, Nusrat, \& Aziz, 2011). However, the same study also reported that $88 \%$ of newborns were deficient in vitamin D, which aligns with our findings for newborns in our control group (Karim et al., 2011). Studies which have explored vitamin D deficiency among women of reproductive age have shown that hypovitaminosis is more prevalent in pregnant women than in non-pregnant women, making the need for supplementation greater among pregnant women. The recent National Nutrition Survey in Pakistan (2018) also showed a deficiency of vitamin D 
among women of reproductive age at $79.7 \%$, with a higher prevalence in urban areas (Government of Pakistan \& UNICEF, 2019).

The recommended dose of vitamin $D$ supplementation required during pregnancy remains debatable (Mulligan, Felton, Riek, \& Bernal-Mizrachi, 2010). Our study observed safety and effectiveness of vitamin D supplementation of $2000 \mathrm{IU} /$ day in decreasing vitamin D deficiency, similar to a study conducted in India (Mir et al., 2016). However, we also observed that supplementing $2000 \mathrm{IU} /$ day was not enough to significantly reduce vitamin $D$ deficiency in our study population. Our study showed the greatest improvement in serum vitamin D level among mothers in the $4000 \mathrm{IU}$ group and their newborns as compared to other groups. As per our knowledge, only a few studies have observed health outcomes with $4000 \mathrm{IU} /$ day of supplementation (Dawodu et al., 2013; B. W. Hollis et al., 2011; Hossain et al., 2014; F. R. Khan et al., 2016; Roth et al., 2018; Carol L. Wagner et al., 2013). All studies reported safety and effectiveness of supplementing women with $4000 \mathrm{IU} /$ day of vitamin $D$ in improving serum vitamin $D$ levels in pregnant women and newborns compared to control groups or groups with lower dosage of vitamin D supplementation. Moreover, no study reported a significant increase of higher adverse events with higher supplementation. Our findings support previous studies mentioned above, which have proven that 4000 IU/day of vitamin $D$ supplementation is safe and effective in reducing vitamin $D$ deficiency in pregnant women and newborns and has the most impact compared to supplementing $2000 \mathrm{IU} /$ day or the recommended $400 \mathrm{IU} /$ day

The relationship between Vitamin D deficiency and GDM has been described frequently in literature (Zhang et al., 2008) Similar to a study conducted in neighbouring countries, our study also found an insignificant effect of vitamin D supplementation on GDM (Asemi, Samimi, Tabassi, Shakeri, \& Esmaillzadeh, 2013; Sablok et al., 2015; Tehrani, Mostajeran, \& Banihashemi, 2017). The same effect of vitamin $D$ was seen on incidence of pre-eclampsia, where although groups receiving a higher dose of vitamin D presented fewer cases of pre-eclampsia, the overall occurrence of pre-eclampsia and the difference between groups was not significant (Asemi et al., 2013; Naghshineh \& Sheikhaliyan, 2016; Sablok et al., 2015; Sasan, Zandvakili, Soufizadeh, \& Baybordi, 2017).

Our study failed to find any difference in the occurrence of preterm birth among women who received the highest supplementation of vitamin D. Meta-analyses among systematic reviews have shown conflicting results for this outcome. A meta-analysis of three trials found a lower risk of preterm birth among women who received vitamin D supplementation, whereas another meta-analysis of thirteen trials and one of seven trials found no effect, which aligned with our study findings (De-Regil et al., 2016; C. Palacios et al., 2019; Roth et al., 2017). Moreover, a meta-analysis of only observational studies found that the presence of vitamin $D$ deficiency was associated with a higher risk of preterm birth in pregnant women (Qin, Lu, Yang, Xu, \& Luo, 2016). Compared to the limited research available, our study results indicate that supplementation does not protect against the occurrence of preterm birth. For the occurrence of low birth weight, our results also show no difference in its prevalence among neonates whose mothers received vitamin D supplementation, which was seen in a meta-analyses of seven studies (Roth et al., 2017). However, another meta-analyses of five studies found lower odds of low birth weight in newborns whose 
mothers took vitamin D supplementation during pregnancy (C. Palacios et al., 2019). Most meta-analyses conducted on randomized trials of vitamin $\mathrm{D}$ supplementation have shown uncertain impacts of supplementation on maternal and neonatal outcomes. This could be attributed to methodological heterogeneity among studies and differences in vitamin D dosages across randomized, controlled trials. Although meta-analyses give weightage to studies according to their sample size, it is equally important to identify the association between serum $250 H(D)$ levels, vitamin D deficiency and adverse outcomes. Despite the debate over the impact of vitamin D supplementation, our study supports earlier findings where administering a supplementation of $4000 \mathrm{IU} /$ day did not result in congenital abnormalities, serious adverse events or adverse maternal and neonatal outcomes (Bi et al., 2018; Vieth, Chan, \& MacFarlane, 2001).

Despite adequate exposure to sunlight in households and time spent under the sun, we found that vitamin $D$ deficiency was still high among women enrolled in our study. This could be attributable to their dressing and their diet, although food sources have very little vitamin D content. Almost all women in our study wore a veil/burqa when outside their house, which has been associated with low absorption of sunlight and therefore, low vitamin D status in several studies conducted in Islamic countries (Alagöl et al., 2000; Mishal, 2001; Moeness Moustafa, 2012; Prentice, Schoenmakers, Jones, Jarjou, \& Goldberg, 2009). Moreover, food consumption for sources that provide vitamin $D$ and calcium among women were inadequate with only $20-30 \%$ women consuming atleast five essential food groups. Another point to note is that although many countries fortify milk and milk products with vitamin D, milk in Pakistan is mostly unpackaged and untreated with fortified minerals. Therefore, dietary practices in Pakistan do not provide sufficient vitamin $D$, which also results in calcium deficiency among women, as seen in our study.

Our study had some limitations. First, we were unable to capture thorough neonatal anthropometric measures and assess the impact of vitamin D supplementation on neonatal anthropometry. Second, our recommendations and results that generate from this study may not be generalizable to a global population due to the severity of vitamin D deficiency in Pakistan compared to the rest of the world. In order to attain normal $250 \mathrm{H}(\mathrm{D})$ levels from baseline likely required a higher dosage of supplementation compared to what is required among other populations (Hossain et al., 2014). Third, our results did not produce significant differences for pregnancy and birth outcomes across different intervention groups. This is possibly due to our underpowered sample size towards the end of the study. Although we recruited more participants than needed, about a quarter of them did not complete the study.

In conclusion, the evidence presented in our study indicates an association between vitamin $D$ supplementation of $4000 \mathrm{IU} /$ day and adequate maternal and neonatal serum vitamin D levels in gravidae who are deficient in vitamin D. Supplementation also attenuated the occurrence of low birthweight and preterm birth. However, due to a high prevalence of calcium deficiency, more robust and comprehensive trials are required from different parts of the country to identify an overall impact of vitamin D supplementation while also ensuring adequate calcium levels among women. Moreover, studies would benefit by following up with newborns of mothers enrolled in supplementation trials to identify long-term outcomes and benefits of supplementation.

Page 10/21 


\section{Declarations}

\section{Funding Information}

This study was funded by the University Research Council at the Aga Khan University, Pakistan.

\section{Conflicts of Interest}

The authors declare no conflicts of interest

\section{Author Contributions}

SN was the principal investigator of the study and wrote the first draft of the manuscript. SN and SS conceptualized study idea \& design and interpreted the data, FT supervised data collection activities. AR and FS contributed in data management and analysis. LS, AH, MB and SR critically reviewed the manuscript. All authors contributed in manuscript review and approved the final manuscript.

\section{References}

Agarwal, S., Kovilam, O., \& Agrawal, D. K. (2018). Vitamin D and its impact on maternal-fetal outcomes in pregnancy: A critical review. Critical Reviews in Food Science and Nutrition, 58(5), 755-769. doi:10.1080/10408398.2016.1220915

Aghajafari, F., Nagulesapillai, T., Ronksley, P. E., Tough, S. C., O’beirne, M., \& Rabi, D. M. (2013). Association between maternal serum 25-hydroxyvitamin $\mathrm{D}$ level and pregnancy and neonatal outcomes: systematic review and meta-analysis of observational studies. BMJ : British Medical Journal, 346(7902). doi:10.1136/bmj.f1169

Akhtar, S. (2016). Vitamin D Status in South Asian Populations - Risks and Opportunities. Crit Rev Food Sci Nutr, 56(11), 1925-1940. doi:10.1080/10408398.2013.807419

Alagöl, F., Shihadeh, Y., Boztepe, H., Tanakol, R., Yarman, S., Azizlerli, H., \& Sandalci, Ö. (2000). Sunlight exposure and vitamin D deficiency in Turkish women. Journal of Endocrinological Investigation, 23(3), 173-177. doi:10.1007/BF03343702

American Diabetes Association. (2012). Diagnosis and Classification of Diabetes Mellitus. Diabetes Care, 35(Supplement 1), S64-S71. doi:10.2337/dc12-s064

Anwar, S., Iqbal, M. P., Azam, I., Habib, A., Bhutta, S., Soofi, S. B., \& Bhutta, Z. A. (2016). Urban and rural comparison of vitamin D status in Pakistani pregnant women and neonates. Journal of Obstetrics and Gynaecology, 36(3), 318-323. doi:10.3109/01443615.2015.1050647

Asemi, Z., Samimi, M., Tabassi, Z., Shakeri, H., \& Esmaillzadeh, A. (2013). Vitamin D supplementation affects serum high-sensitivity $\mathrm{C}$-reactive protein, insulin resistance, and biomarkers of oxidative stress in 
pregnant women. The Journal of Nutrition, 143(9), 1432. doi:10.3945/jn.113.177550

Bassil, D., Rahme, M., Hoteit, M., \& Fuleihan, G. E.-H. (2013). Hypovitaminosis D in the Middle East and North Africa: Prevalence, risk factors and impact on outcomes. Dermato-endocrinology, 5(2), 274-298. doi:10.4161/derm.25111

Bi, W., Nuyt, A., Weiler, H., Leduc, L., Santamaria, C., \& Wei, S. (2018). Association Between Vitamin D Supplementation During Pregnancy and Offspring Growth, Morbidity, and Mortality A Systematic Review and Meta-analysis. Jama Pediatrics, 172(7), 635-645. doi:10.1001/jamapediatrics.2018.0302

Bikle, Daniel d. (2014). Vitamin D Metabolism, Mechanism of Action, and Clinical Applications. Chemistry \& Biology, 21(3), 319-329. doi:10.1016/j.chembiol.2013.12.016

Christakos, S. (2012). Mechanism of action of 1,25-dihydroxyvitamin D 3 on intestinal calcium absorption. Reviews in Endocrine and Metabolic Disorders, 13(1), 39-44. doi:10.1007/s11154-011-9197-x

Dawodu, F. A., Saadi, W. H., Bekdache, W. G., Javed, W. Y., Altaye, W. M., \& Hollis, W. B. (2013). Randomized Controlled Trial (RCT) of Vitamin D Supplementation in Pregnancy in a Population With Endemic Vitamin D Deficiency. The Journal of Clinical Endocrinology \& Metabolism, 98(6), 2337-2346. doi:10.1210/jc.2013-1154

De-Regil, L., Palacios, C., Lombardo, L., \& Pena-Rosas, J. P. (2016). Vitamin D supplementation for women during pregnancy. Cochrane Database Of Systematic Reviews, 2016(1). doi:10.1002/14651858.CD008873.pub3

Gallo, S., McDermid, J. M., Al-Nimr, R. I., Hakeem, R., Moreschi, J. M., Pari-Keener, M., . . Cheng, F. W. (2019). Vitamin D Supplementation during Pregnancy: An Evidence Analysis Center Systematic Review and Meta-Analysis. Journal of the Academy of Nutrition and Dietetics. doi:10.1016/j.jand.2019.07.002

Government of Pakistan. (2013). National Nutrition Survey 2011. Retrieved from Islamabad, Pakistan: Government of Pakistan, \& UNICEF. (2019). National Nutrition Survey 2018 - Key Findings Report. In. Islamabad, Pakistan: UNICEF Pakistan.

Holick, M. F. (2007). Vitamin D deficiency. The New England Journal of Medicine, 357(3), 266. doi:10.1056/NEJMra070553

Holick, M. F., \& Chen, T. C. (2008). Vitamin D deficiency: a worldwide problem with health consequences. American Journal of Clinical Nutrition, 87(4), 1080S-1086S. doi:10.1093/ajcn/87.4.1080S

Hollis, B., \& Wagner, C. (2004). Assessment of dietary vitamin D requirements during pregnancy and lactation. American Journal Of Clinical Nutrition, 79(5), 717-726. doi:10.1093/ajcn/79.5.717 
Hollis, B. W., Johnson, D., Hulsey, T. C., Ebeling, M., \& Wagner, C. L. (2011). Vitamin D supplementation during pregnancy: Double-blind, randomized clinical trial of safety and effectiveness. Journal of Bone and Mineral Research, 26(10), 2341-2357. doi:10.1002/jbmr.463

Hossain, H. N., Kanani, H. F., Ramzan, H. S., Kausar, H. R., Ayaz, H. S., Khanani, H. R., \& Pal, H. L. (2014). Obstetric and Neonatal Outcomes of Maternal Vitamin D Supplementation: Results of an Open-Label, Randomized Controlled Trial of Antenatal Vitamin D Supplementation in Pakistani Women. The Journal of Clinical Endocrinology \& Metabolism, 99(7), 2448-2455. doi:10.1210/jc.2013-3491

Hossein-Nezhad, A., \& Holick, M. F. (2013). Vitamin D for Health: A Global Perspective. Mayo Clinic Proceedings, 88(7), 720-755. doi:10.1016/j.mayocp.2013.05.011

Institute of Medicine, C. t. R. D. R. I. f. V. D. a. C. (2011). Dietary Reference Intakes for Calcium and Vitamin $D$. Washington (DC): National Academies Press.

Karim, S. A., Nusrat, U., \& Aziz, S. (2011). Vitamin D deficiency in pregnant women and their newborns as seen at a tertiary-care center in Karachi, Pakistan. International Journal of Gynecology \& Obstetrics, 112(1), 59-62. doi:10.1016/j.ijgo.2010.07.034

Kazemi, A., Sharifi, F., Jafari, N., \& Mousavinasab, N. (2009). High prevalence of vitamin D deficiency among pregnant women and their newborns in an Iranian population. Journal of women's health (2002), 18(6), 835. doi:10.1089/jwh.2008.0954

Khan, A., Naureen, G., lqbal, R., \& Dar, F. (2013). Assessing the effect of dietary calcium intake and 25 OHD status on bone turnover in women in Pakistan. Archives of Osteoporosis, 8(1), 1-8. doi:10.1007/s11657013-0151-2

Khan, F. R., Ahmad, T., Hussain, R., \& Bhutta, Z. A. (2016). A Randomized Controlled Trial of Oral Vitamin D Supplementation in Pregnancy to Improve Maternal Periodontal Health and Birth Weight. Journal of International Oral Health, 8(6), 657-665. doi:10.2047/jioh-08-06-03

Kumar, R., \& Thompson, Jr. (2011). The Regulation of Parathyroid Hormone Secretion and Synthesis. Journal Of The American Society Of Nephrology, 22(2), 216-224. doi:10.1681/ASN.2010020186

Lowe, N., \& Bhojani, I. (2017). Special considerations for vitamin D in the south Asian population in the UK. In Ther. Adv. Musculoskelet. Dis. (Vol. 9, pp. 137-144).

Maghbooli, Z., Hossein-Nezhad, A., Shafaei, A. R., Karimi, F., Madani, F. S., \& Larijani, B. (2007). Vitamin D status in mothers and their newborns in Iran. BMC Pregnancy and Childbirth, 7(1), 1-1. doi:10.1186/14712393-7-1

Merewood, A., Mehta, S. D., Chen, T. C., Bauchner, H., \& Holick, M. (2009). Association between Vitamin D Deficiency and Primary Cesarean Section. Journal Of Clinical Endocrinology \& Metabolism, 94(3), 940945. doi:10.1210/jc.2008-1217 
Mir, S., Masoodi, S., Shafi, S., Hameed, I., Dar, M., Bashir, M., . . Shah, P. (2016). Efficacy and safety of Vitamin D supplementation during pregnancy: A randomized trial of two different levels of dosing on maternal and neonatal Vitamin D outcome. Indian Journal of Endocrinology and Metabolism, 20(3), 337342. doi:10.4103/2230-8210.179991

Mishal, A. A. (2001). Effects of Different Dress Styles on Vitamin D Levels in Healthy Young Jordanian Women. Osteoporosis International, 12(11), 931-935. doi:10.1007/s001980170021

Mithal, A., \& Kalra, S. (2014). Vitamin D supplementation in pregnancy. Indian Journal of Endocrinology and Metabolism, 18(5), 593-596. doi:10.4103/2230-8210.139204

Moeness Moustafa, A. (2012). Vitamin D Deficiency; This clandestine endemic disease is veiled no more. Sultan Qaboos University Medical Journal, 12(2), 140-152. doi:10.12816/0003106

Mulligan, M. L., Felton, S. K., Riek, A. E., \& Bernal-Mizrachi, C. (2010). Implications of vitamin D deficiency in pregnancy and lactation. Am J Obstet Gynecol, 202(5), 429.e421-429. doi:10.1016/j.ajog.2009.09.002

Naghshineh, E., \& Sheikhaliyan, S. (2016). Effect of vitamin D supplementation in the reduce risk of preeclampsia in nulliparous women. Advanced Biomedical Research, 5(1), 7-7. doi:10.4103/22779175.175239

Olmos-Ortiz, A., Avila, E., Durand-Carbajal, M., \& Díaz, L. (2015). Regulation of Calcitriol Biosynthesis and Activity: Focus on Gestational Vitamin D Deficiency and Adverse Pregnancy Outcomes. Nutrients, 7(1), 443-480. doi:10.3390/nu7010443

Palacios, C., \& Gonzalez, L. (2014). Is vitamin D deficiency a major global public health problem? Journal of Steroid Biochemistry and Molecular Biology, 144, 138-145. doi:10.1016/j.jsbmb.2013.11.003

Palacios, C., Kostiuk, L., \& Pena-Rosas, J. P. (2019). Vitamin D supplementation for women during pregnancy. Cochrane Database Of Systematic Reviews, 7(7). doi:10.1002/14651858.CD008873.pub4

Panda, M., Mclntosh, J., Chaudhari, T., \& Kent, A. L. (2019). Do Maternal Vitamin D Levels Influence Vitamin D Levels in Preterm Neonates? International Journal of Pediatrics, 2019. doi:10.1155/2019/8613414

Prentice, A. (2008). Vitamin D deficiency: a global perspective. Nutrition Reviews, 66(10), S153-S164. doi:10.1111/j.1753-4887.2008.00100.x

Prentice, A., Schoenmakers, I., Jones, K., Jarjou, L., \& Goldberg, G. (2009). Vitamin D Deficiency and Its Health Consequences in Africa. Clinical Reviews in Bone and Mineral Metabolism, 7(1), 94-106. doi:10.1007/s12018-009-9038-6

Qin, L.-L., Lu, F.-G., Yang, S.-H., Xu, H.-L., \& Luo, B.-A. (2016). Does Maternal Vitamin D Deficiency Increase the Risk of Preterm Birth: A Meta-Analysis of Observational Studies. Nutrients, 8(5), 301. 
Roth, D. E., Al Mahmud, A., Raqib, R., Akhtar, E., Perumal, N., Pezzack, B., \& Baqui, A. H. (2013).

Randomized placebo-controlled trial of high-dose prenatal third-trimester vitamin D3 supplementation in Bangladesh: the AViDD trial. Nutrition Journal, 12(1). doi:10.1186/1475-2891-12-47

Roth, D. E., Leung, M., Mesfin, E., Qamar, H., Watterworth, J., \& Papp, E. (2017). Vitamin D supplementation during pregnancy: state of the evidence from a systematic review of randomised trials. BMJ, 359. doi:10.1136/bmj.j5237

Roth, D. E., Morris, S. K., Zlotkin, S., Gernand, A. D., Ahmed, T., Shanta, S. S., . . Pell, L. G. (2018). Vitamin D Supplementation in Pregnancy and Lactation and Infant Growth. The New England Journal of Medicine, 379(6), 535-546. doi:10.1056/NEJMoa1800927

Sablok, A., Batra, A., Thariani, K., Batra, A., Bharti, R., Aggarwal, A. R., ... Chellani, H. (2015).

Supplementation of vitamin $\mathrm{D}$ in pregnancy and its correlation with feto-maternal outcome. Clinical Endocrinology, 83(4), 536-541. doi:10.1111/cen.12751

Sasan, S. B., Zandvakili, F., Soufizadeh, N., \& Baybordi, E. (2017). The Effects of Vitamin D Supplement on Prevention of Recurrence of Preeclampsia in Pregnant Women with a History of Preeclampsia. Obstetrics and Gynecology International, 2017. doi:10.1155/2017/8249264

St-Arnaud, R., \& Naja, R. P. (2011). Vitamin D metabolism, cartilage and bone fracture repair. Molecular and Cellular Endocrinology, 347(1-2), 48-54. doi:10.1016/j.mce.2011.05.018

Tehrani, H., Mostajeran, F., \& Banihashemi, B. (2017). Effect of Vitamin D Supplementation on the Incidence of Gestational Diabetes. Advanced Biomedical Research, 6(1), 79-79. doi:10.4103/22779175.210658

Tibbott, R., Camadoo, L., \& Isaza, F. (2007). Maternal vitamin D deficiency associated with neonatal hypocalcaemic convulsions. Nutrition Journal, 6(1), 23. doi:10.1186/1475-2891-6-23

VanPool, T. L., \& Leonard, R. D. (2011). Quantitative Analysis in Archaeology. In T. L. L. VanPool, Robert D. (Ed.), (pp. 238-261). Malden, MA: Wiley-Blackwell.

Vatandost, S., Jahani, M., Afshari, A., Amiri, M. R., Heidarimoghadam, R., \& Mohammadi, Y. (2018). Prevalence of vitamin D deficiency in Iran: A systematic review and meta-analysis. Nutrition and Health, 24(4), 269-278. doi:10.1177/0260106018802968

Vieth, R., Chan, P. C. R., \& MacFarlane, G. D. (2001). Efficacy and safety of vitamin D 3 intake exceeding the lowest observed adverse effect level. American Journal of Clinical Nutrition, 73(2), 288-294.

doi:10.1128/AEM.67.2.1015-1019.2001 
Wagner, C. L., Baggerly, C., McDonnell, S. L., Baggerly, L., Hamilton, S. A., Winkler, J., . . Hollis, B. W. (2015). Post-hoc comparison of vitamin D status at three timepoints during pregnancy demonstrates lower risk of preterm birth with higher vitamin D closer to delivery. Journal of Steroid Biochemistry and Molecular Biology, 148, 256-260. doi:10.1016/j.jsbmb.2014.11.013

Wagner, C. L., McNeil, R. B., Johnson, D. D., Hulsey, T. C., Ebeling, M., Robinson, C., . . Hollis, B. W. (2013). Health characteristics and outcomes of two randomized vitamin $D$ supplementation trials during pregnancy: A combined analysis. Journal of Steroid Biochemistry and Molecular Biology, 136(1), 313320. doi:10.1016/j.jsbmb.2013.01.002

Wagner, L. K. (2004). Diagnosis and management of preeclampsia. American family physician, 70(12), 2317.

Wei, S.-Q., Qi, H.-P., Luo, Z.-C., \& Fraser, W. D. (2013). Maternal vitamin D status and adverse pregnancy outcomes: a systematic review and meta-analysis. The Journal of Maternal-Fetal \& Neonatal Medicine, 26(9), 889-899. doi:10.3109/14767058.2013.765849

World Health Organization. (2016). WHO recommendations on antenatal care for a positive pregnancy experience. Retrieved from Geneva:

https://apps.who.int/iris/bitstream/handle/10665/250796/9789241549912-eng.pdf?sequence=1

Zhang, C., Qiu, C., Hu, F. B., David, R. M., van Dam, R. M., Bralley, A., \& Williams, M. A. (2008). Maternal Plasma 25-Hydroxyvitamin D Concentrations and the Risk for Gestational Diabetes Mellitus (Vitamin D and GDM). PLoS ONE, 3(11), e3753. doi:10.1371/journal.pone.0003753

\section{Tables}

Table 1 - Baseline socioeconomic and clinical characteristics of women participating in the study at enrolment, by study group. 


\begin{tabular}{|c|c|c|c|c|c|}
\hline & $\begin{array}{l}\text { Group A } \\
(\mathrm{n}=120)\end{array}$ & $\begin{array}{l}\text { Group B } \\
(\mathrm{n}=115)\end{array}$ & $\begin{array}{l}\text { Group C } \\
(\mathrm{n}=115)\end{array}$ & Total $(n=350)$ & p-value ${ }^{a}$ \\
\hline Age, years ${ }^{b}$ & $25.58 \pm 3.9$ & $25.96 \pm 4.5$ & $26.57 \pm 4.3$ & $26.03 \pm 4.3$ & 0.207 \\
\hline Gestational Age (weeks) $^{\mathrm{b}}$ & $13.2 \pm 4.4$ & $13.4 \pm 4.6$ & $13.3 \pm 4.3$ & $13.3 \pm 4.4$ & 0.954 \\
\hline \multicolumn{6}{|l|}{ Respondent's education ${ }^{c}$} \\
\hline Primary & 19 (15.8) & 17 (14.8) & 15 (13) & $51(14.6)$ & 0.917 \\
\hline Middle & $43(35.8)$ & $47(40.9)$ & $45(39.1)$ & $135(38.6)$ & \\
\hline Matric and above & $58(48.3)$ & $51(44.3)$ & $55(47.8)$ & $164(46.9)$ & \\
\hline \multicolumn{6}{|l|}{ Husband's Education ${ }^{c}$} \\
\hline Primary & $7(5.8)$ & $12(10.4)$ & $14(12.2)$ & $33(9.4)$ & 0.141 \\
\hline Middle & $39(32.5)$ & $48(41.7)$ & $36(31.3)$ & $123(35.1)$ & \\
\hline Matric and above & $74(61.7)$ & $55(47.8)$ & $65(56.5)$ & $194(55.4)$ & \\
\hline \multicolumn{6}{|l|}{ Husband's Occupation ${ }^{c}$} \\
\hline Business & $32(26.7)$ & $37(32.2)$ & $37(32.2)$ & $106(30.3)$ & 0.298 \\
\hline Labourer & $15(12.5)$ & $18(15.7)$ & $19(16.5)$ & $52(14.9)$ & \\
\hline Govt/Private & $69(57.5)$ & $53(46.1)$ & 49 (42.6) & $171(48.9)$ & \\
\hline Other & $4(3.3)$ & $7(6.1)$ & $10(8.7)$ & $21(6)$ & \\
\hline Husband's Average Income (PKR) ${ }^{b}$ & $21483 \pm 12910$ & $19430 \pm 11608$ & $20379 \pm 12497$ & $20446 \pm 12352$ & 0.445 \\
\hline \multicolumn{6}{|l|}{ Anthropometry ${ }^{b}$} \\
\hline Height $(\mathrm{cm})$ & $152.1 \pm 9.8$ & $152.5 \pm 10.2$ & $154.2 \pm 6.1$ & $152.9 \pm 8.9$ & 0.170 \\
\hline Weight (kg) & $66.36 \pm 12.55$ & $70.75 \pm 15.68$ & $70.09 \pm 13.17$ & $69.16 \pm 13.9$ & 0.095 \\
\hline $\mathrm{BMI}\left(\mathrm{kg} / \mathrm{m}^{2}\right)$ & $28.3 \pm 5.4$ & $30.1 \pm 6.7$ & $29.7 \pm 5.4$ & $29.4 \pm 5.9$ & 0.133 \\
\hline \multicolumn{6}{|l|}{ Exposure to Vitamin $\mathrm{D}^{\mathrm{c}}$} \\
\hline Household receives adequate amount of sunlight & $111(92.5)$ & $109(94.8)$ & $106(92.2)$ & 326 (93.1) & 0.694 \\
\hline Usually wear veil/burqa when outside house & $117(97.5)$ & $112(97.4)$ & $108(93.9)$ & $337(96.3)$ & 0.259 \\
\hline Maternal Diet ${ }^{d}$ & $\mathrm{n}=117$ & $\mathrm{n}=115$ & $\mathrm{n}=104$ & $\mathrm{n}=336$ & \\
\hline Food groups consumed $^{\mathrm{b}}$ & $3.83 \pm 1.13$ & $3.69 \pm 1.12$ & $3.69 \pm 1.01$ & $3.74 \pm 1.09$ & 0.557 \\
\hline MDD-W ${ }^{c e}$ & $29(24.8)$ & $25(21.7)$ & $20(19.2)$ & $75(22.3)$ & 0.607 \\
\hline
\end{tabular}

Group A = $4000 \mathrm{IU} /$ day, Group B = $2000 \mathrm{IU} /$ day, Group C = $400 \mathrm{IU} /$ day (control group)

a P-values for continuous variables using ANOVA; categorical variable P-values are from chi-squared tests

${ }^{b}$ Data presented as mean \pm standard deviation

${ }^{\mathrm{c}}$ Data presented as $\mathrm{n}(\%)$

${ }^{d}$ Food Groups: 1) Grains, white roots, tubers, plantains; 2) Pulses; 3) Nuts and seeds; 4) Dairy; 5) Meat, poultry, fish; 6) Eggs; 7) Dark green leafy vegetables; 8) Vitamin A rich fruits and vegetables; 9) Other vegetables; 10) Other fruits

${ }^{\mathrm{e}} \mathrm{MDD}-\mathrm{W}$ is a dichotomous indicator of whether women have consumed at least five out of ten defined food groups the previous day or night

PKR $=$ Pakistani Rupees

Table 2 - Maternal and neonatal biochemical markers ${ }^{\mathrm{a}}$ and maternal and neonatal biochemical deficiencies ${ }^{\mathrm{b}}$. Maternal markers and deficiencies are assessed at both baseline and endline. Neonatal markers and deficiencies are assessed at birth. 


\begin{tabular}{|c|c|c|c|c|}
\hline $\begin{array}{l}\text { Biochemical } \\
\text { markers }^{\mathrm{a}}\end{array}$ & $\begin{array}{l}\text { Group A } \\
\text { (Baseline: } \mathrm{n}=118 \text {; Final: } \\
\text { n=79; Neonatal: } \mathrm{n}=71 \text { ) }\end{array}$ & $\begin{array}{l}\text { Group B (Baseline: } \mathrm{n}=115 \text {; Final: } \\
\mathrm{n}=86 \text {; Neonatal: } \mathrm{n}=76 \text { ) }\end{array}$ & $\begin{array}{l}\text { Group C (Baseline: } \mathrm{n}=112 \text {; Final: } \\
\mathrm{n}=92 ; \text { Neonatal: } \mathrm{n}=85 \text { ) }\end{array}$ & $\begin{array}{l}\text { p- } \\
\text { value }^{c}\end{array}$ \\
\hline \multicolumn{5}{|l|}{$\begin{array}{l}\text { Vitamin D } \\
\text { (ng/mL) }\end{array}$} \\
\hline Baseline & $8.4 \pm 5.5$ & $9.8 \pm 10.2$ & $7.9 \pm 6.1$ & 0.162 \\
\hline Final & $14.0 \pm 9.6$ & $11.9 \pm 7.7$ & $9.8 \pm 7.2$ & $0.002 *$ \\
\hline Neonatal & $17.4 \pm 13.8$ & $14.5 \pm 11.5$ & $10.2 \pm 7.1$ & $0.006^{*}$ \\
\hline \multicolumn{5}{|l|}{$\begin{array}{l}\text { Calcium } \\
\text { (mg/dL) }\end{array}$} \\
\hline Baseline & $9.5 \pm 2.3$ & $9.1 \pm 2.4$ & $9.3 \pm 2.4$ & 0.470 \\
\hline Final & $8 \pm 2.3$ & $7.8 \pm 2.9$ & $8.2 \pm 2.4$ & 0.675 \\
\hline Neonatal & $8.3 \pm 3.1$ & $8.3 \pm 3.3$ & $8.1 \pm 3$ & 0.908 \\
\hline \multicolumn{5}{|l|}{$\begin{array}{l}\text { Phosphorus } \\
\text { (mg/dL) }\end{array}$} \\
\hline Baseline & $12.1 \pm 7.1$ & $12.2 \pm 5.7$ & $14.3 \pm 6.4$ & $0.014 *$ \\
\hline Final & $16.6 \pm 7.6$ & $16.9 \pm 8$ & $16.9 \pm 7.3$ & 0.953 \\
\hline Neonatal & $23.1 \pm 9.7$ & $25.6 \pm 9.2$ & $22.7 \pm 8.5$ & 0.106 \\
\hline \multicolumn{5}{|l|}{$\begin{array}{l}\text { Alkaline } \\
\text { Phosphate } \\
\text { (U/L) }\end{array}$} \\
\hline Baseline & $77.5 \pm 25.7$ & $76.3 \pm 39$ & $76.4 \pm 31.2$ & 0.955 \\
\hline Final & $158.3 \pm 71$ & $196.4 \pm 206.2$ & $194.7 \pm 164.1$ & 0.223 \\
\hline Neonatal & $248.9 \pm 452.3$ & $320.5 \pm 691.4$ & $211.2 \pm 196.6$ & 0.350 \\
\hline \multicolumn{5}{|l|}{$\begin{array}{l}\text { Biochemical } \\
\text { deficiencies }^{b}\end{array}$} \\
\hline \multicolumn{5}{|l|}{$\begin{array}{l}\text { Vitamin D } \\
\text { deficiency } \\
(<20 \mathrm{ng} / \mathrm{mL})\end{array}$} \\
\hline Baseline & 116 (97.5) & 109 (94.8) & 107 (95.5) & 0.553 \\
\hline Final & 60 (75.9) & $73(84.9)$ & $83(90.2)$ & $0.006^{*}$ \\
\hline Neonatal & $48(64.9)$ & $56(73.7)$ & $78(91.8)$ & $0.001 *$ \\
\hline \multicolumn{5}{|l|}{$\begin{array}{l}\text { Calcium } \\
\text { Deficiency } \\
\text { (<8.6 mg/dL) }\end{array}$} \\
\hline Baseline & 37 (31.4) & 41 (35.7) & 33 (29.5) & 0.670 \\
\hline Final & 45 (56.9) & $46(53.5)$ & $54(58.7)$ & 0.710 \\
\hline Neonatal & $39(54.9)$ & $37(48.7)$ & $47(55.3)$ & 0.362 \\
\hline
\end{tabular}

Group A = $4000 \mathrm{IU} /$ day, Group B = $2000 \mathrm{IU} /$ day, Group C = $400 \mathrm{IU} /$ day (control group)

a Data presented as mean \pm standard deviation.

${ }^{b}$ Data presented as n (\%).

${ }^{c} \mathrm{P}$-values for continuous variables using ANOVA; categorical variable P-values are from chi-squared tests

* Significant difference between groups

Table 3 - Pregnancy and birth outcomes and exposure to Vitamin D (compliance to supplementation and food frequency) among participating women 


\begin{tabular}{|c|c|c|c|c|c|}
\hline Clinical Outcomes $^{\mathrm{b}}$ & Group A (n=79) & Group B $(n=85)$ & Group C $(n=89)$ & Total $(n=253)$ & p-value ${ }^{a}$ \\
\hline Pre-term birth ${ }^{\mathrm{d}}$ & $23(29.1)$ & $20(23.5)$ & $31(34.8)$ & $74(29.2)$ & 0.284 \\
\hline Low birth weighte & $14(17.7)$ & $19(22.4)$ & $15(16.9)$ & $48(19.0)$ & 0.609 \\
\hline Pre-eclampsia ${ }^{\mathrm{f}}$ & $1(1.3)$ & $1(1.2)$ & $2(2.2)$ & $4(1.6)$ & 0.99 \\
\hline Gestational diabetes $^{g}$ & $3(3.3)$ & $6(7.0)$ & $2(2.2)$ & $11(4.3)$ & 0.283 \\
\hline Still Birth & $0(0)$ & $0(0)$ & $2(2.2)$ & $2(0.8)$ & --- \\
\hline \multicolumn{6}{|l|}{ Vitamin D exposure } \\
\hline $\begin{array}{l}\text { Compliance to supplement } \\
\text { Maternal Diet }\end{array}$ & $\begin{array}{l}107(89.2) \\
\mathrm{n}=76\end{array}$ & $\begin{array}{l}98(86.0) \\
\mathrm{n}=86\end{array}$ & $\begin{array}{l}104(94.6) \\
\mathrm{n}=81\end{array}$ & $\begin{array}{l}309(90) \\
\mathrm{n}=243\end{array}$ & 0.054 \\
\hline Food groups consumed $^{b}$ & $4.08 \pm 1.27$ & $3.74 \pm 1.25$ & $3.93 \pm 1.11$ & $3.91 \pm 1.22$ & 0.213 \\
\hline MDD-W $\mathrm{W}^{\mathrm{cj}}$ & $29(38.2)$ & $21(24.4)$ & $25(30.9)$ & $75(30.7)$ & 0.168 \\
\hline
\end{tabular}

a P-values for continuous variables using ANOVA; categorical variable P-values: Fisher exact test if expected value < 5; Chi-square test if expected value $\geq 5$

${ }^{\mathrm{b}}$ Data presented as mean \pm standard deviation.

${ }^{\mathrm{c}}$ Data presented as n (\%).

d Preterm birth identified if birth occurs before 37 weeks gestation

e Low birth weight defined for neonatal weight $\leq 2500 \mathrm{~g}$ at birth

${ }^{\mathrm{f}}$ Pre-eclampsia identified through blood pressure $>140 / 90 \mathrm{~mm} / \mathrm{Hg}$ and proteinuria $(\geq 300 \mathrm{mg})$

${ }^{g}$ Diagnosed through glucose intolerance during an oral glucose tolerance test

h Participant numbers are the following: Group $A=117$, Group B=115, Group C=104

${ }^{i}$ Food Groups: 1) Grains, white roots, tubers, plantains; 2) Pulses; 3) Nuts and seeds; 4) Dairy; 5) Meat, poultry, fish; 6) Eggs; 7) Dark green leafy vegetables; 8) Vitamin A rich fruits and vegetables; 9) Other vegetables; 10) Other fruits

${ }^{\mathrm{j}} \mathrm{MDD}-\mathrm{W}$ is a dichotomous indicator of whether women have consumed at least five out of ten defined food groups the previous day or night

\section{Figures}




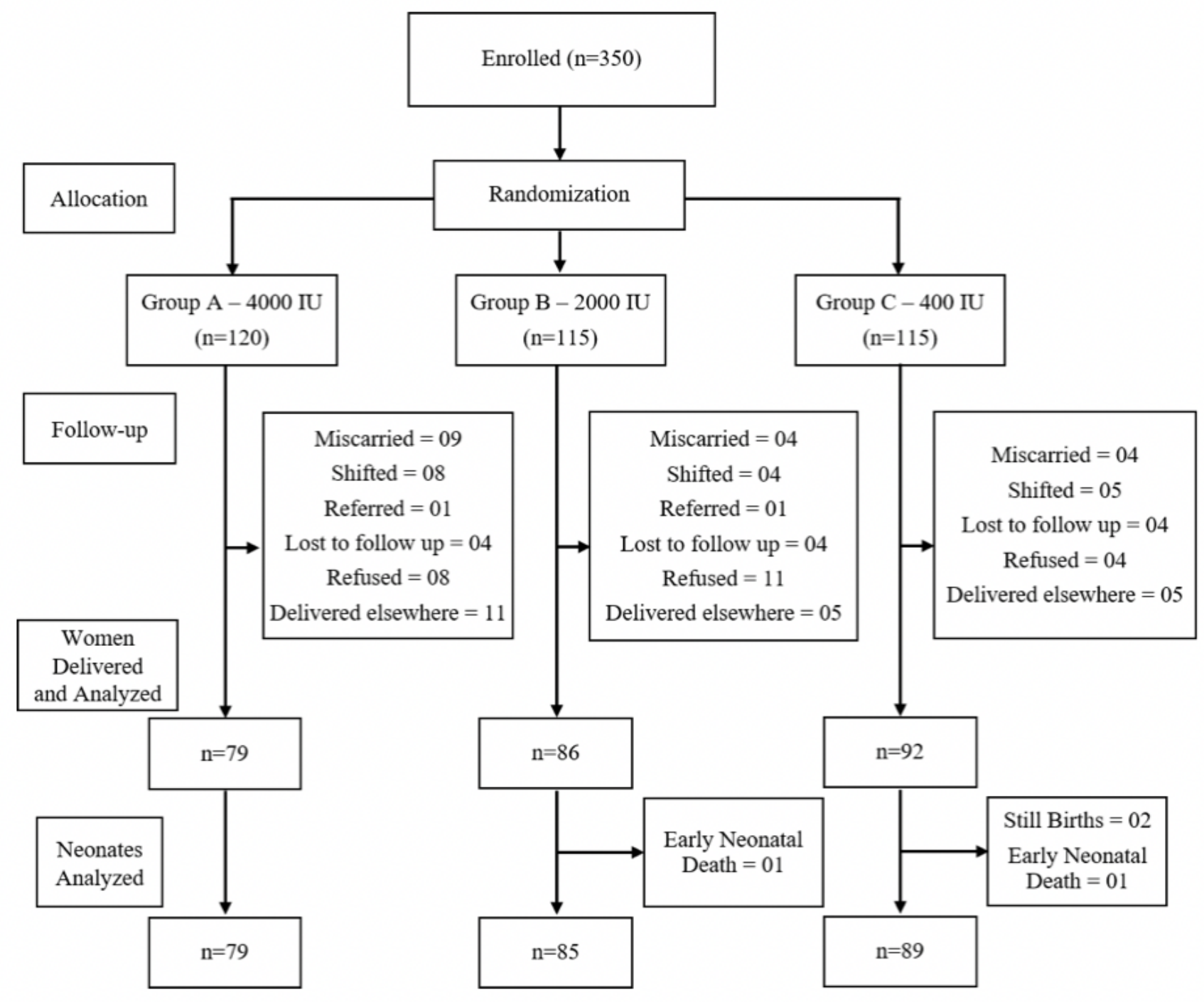

Figure 1

CONSORT diagram of participant enrollment, allocation, follow-up visits and analysis 

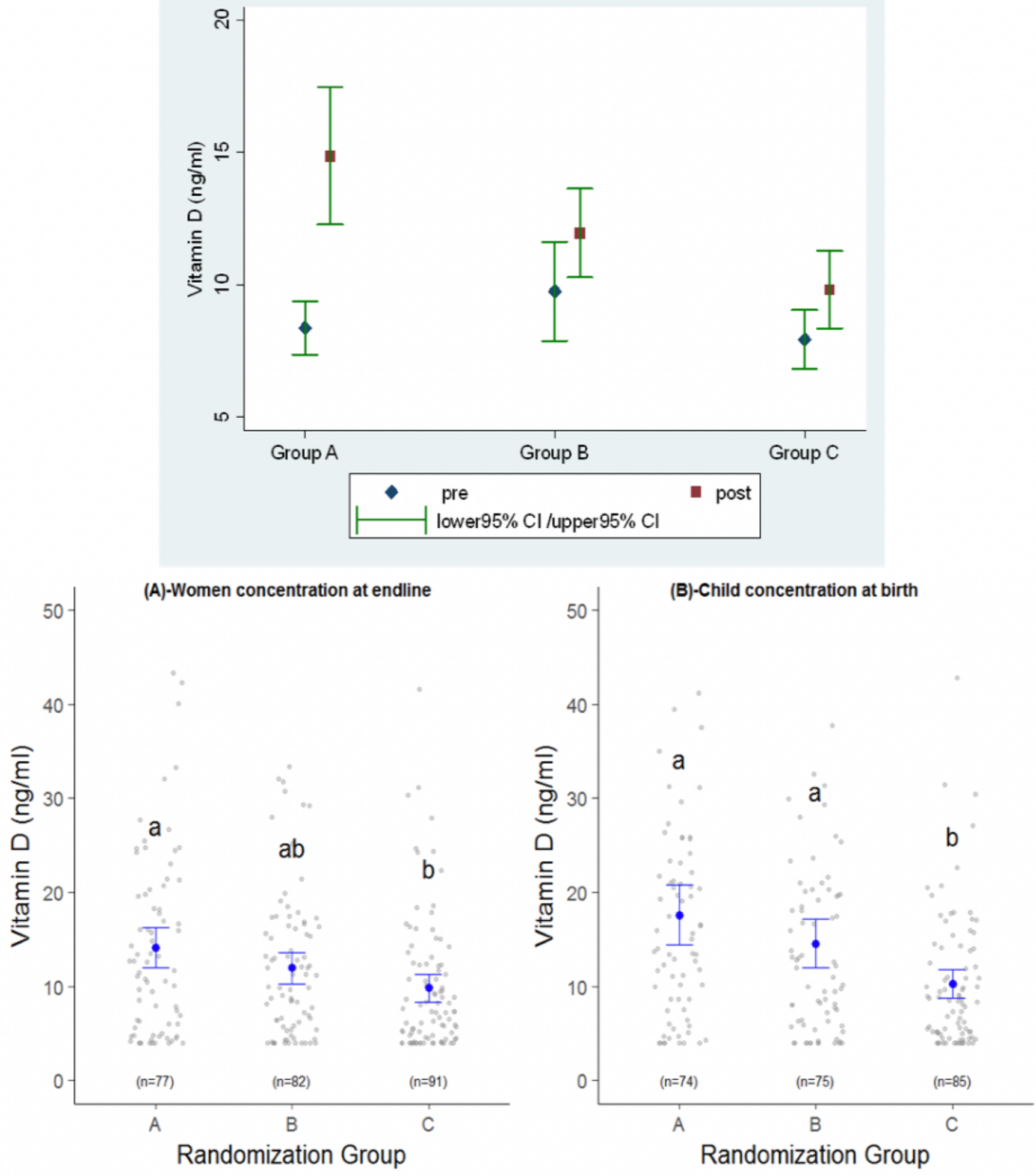

\section{Figure 2}

Blood Vitamin $\mathrm{D}(\mathrm{ng} / \mathrm{mL})$ concentrations in women and their newborns across intervention groups. Vitamin D concentrations between baseline and endline in pregnant women (top), at endline in women and in their newborns (bottom). Different letters indicate significant difference between groups at endline. 